“(C) 2015 IEEE. Personal use of this material is permitted. Permission from IEEE must be obtained for all other uses, in any current or future media, including reprinting/republishing this material for advertising or promotional purposes, creating new collective works, for resale or redistribution to servers or lists, or reuse of any copyrighted component of this work in other works." 


\section{Relationship Development with Customers on Facebook: A Critical Success Factors Model}

\author{
Babak Abedin \\ University of Technology Sydney, Australia \\ Babak.Abedin@uts.edu.au
}

\author{
Hamed Jafarzadeh \\ University of Queensland, Australia \\ H.Jafarzadeh@uq.edu.au
}

\begin{abstract}
Social Networking Sites have been increasingly used by organizations to communicate with and manage relationship with existing and new customers. Through a review of the literature, content analysis of online discussions, and a set of interviews with SNS experts, this study has developed a critical success factor model for effective customer relationship management on Facebook. The model suggests seven critical factors: (i) Develop a strategic SNS plan, (ii) Ability to measure and monitor outcomes, (iii) Integrating SNS activities with other forms of marketing, (iv) Let the users/consumers participate, (v) Being committed to SNS task, (vi) Regular updates on the SNS, and (vii) Try to be honest and authentic during the campaign.
\end{abstract}

\section{Introduction}

With currently more than $60 \%$ of Internet users involved in social networking sites (SNSs) and three SNSs appearing in the world's top 10 visited websites in 2013, more organizations use SNSs' tools for advertisement and communication with users. Social networking sites such as Facebook enhance the level of collaboration between users by allowing them to connect with friends or colleagues, recommend links, and use software applications [1].

Social relationship management has been defined as "a philosophy and a business strategy, supported by a technology platform, business rules, processes and social characteristics, designed to engage the in a collaborative conversation in order to provide mutually beneficial value in a trusted \& transparent business environment." [2, p.413]. Social CRM is supported by organizational strategies and culture as well as technology platforms and processes, and facilitates engagement and establishes mutually beneficial relationships [3]. Increasing customers' loyalty and building a long-term relationship with them are essential objectives of CRM systems, and social networking sites present a new communication channel for organizations to create value through expanding and supporting long term relationships. SNSs enable organizations to increase customers' loyalty through impacting on their perceived value, satisfaction, and knowledge about products and services [1].

Despite the growing popularity of SNSs, few studies have investigated factors that influence the use of these websites for business [4,5]. While traditional customer relation systems were in control of organizations to manage relationships with customers, with SNSs organizations are no longer in control of this relationship [6]. Instead, customers have now the power to drive the conversation and therefore organizations need to use new strategies to recognize the importance of SNSs by addressing the social aspect of relationship management [7].

The objective of this study is therefore to address this gap by identifying the critical success factors that need to be properly managed, if a business wants to effectively use SNSs for customer relationship management. This study uses a triangular data collection approach, including literature review, interview with SNSs practitioners, and content analysis of an online discussion forum in order to discover what factors are critical for a business that must be given an especial and continual attention to bring about a high social CRM performance.

\section{Background}

\subsection{Literature Review}

Social networking sites are web-based services that allow individuals to (1) construct a public or semipublic profile within a bounded system, (2) articulate a list of other users with whom they share a connection, and (3) view and traverse their list of connections and those made by others within the system [8]. SNSs are slightly different in mechanism, but most of them support their members with various tools and features to enable them to build a sense of community in an 
informal and friendly way [5,9]. Through an SNS, people interact with each other in a common information space and participate in a variety of interactive and social activities such as posting information, photo sharing, tagging, organizing events, and so on [10].

SNSs such as Facebook allow businesses to have a two-way and personal relationship with their customers, compared to the one-way and impersonal connection in other advertising methods. Through initiatives such as group buying, co-purchasing, and spreading word of mouth, social media and SNSs have enabled organizations to establish and strengthen relationship with customers [10]. Research shows that the behavior of people in online social networks is different from their behavior in traditional social networks [11], and accordingly organizations need to improve their knowledge about using SNSs for interacting with their customers [7]. However, organizations have not yet been successful in their adoption of SNSs, since they have a lack of clear understanding of what these websites are, and what forms they can take [4].

\subsection{Critical Success Factor Models}

Critical success factors (CSFs) are "those few things that must go well to ensure success for a manager or an organization, and, therefore, they represent those managerial or enterprise areas that must be given special and continual attention to bring about high performance" [12, p17]. Researchers have intensively used the CSF approach to systematically identify key factors that have to be properly managed by an organization to be able to successfully achieve business objectives. In particular, this approach has been used to determine the important issues for organizations to succeed in offline and online marketing and advertisement plans. For example, Kim et al [13] investigated virtual communities as a marketing channel and analyzed critical success factors related to using this channel for advertisement. Other researchers have examined CSFs in one-to-one web marketing and emphasized on the role of information and communication technology as a critical success factor for marketing products [14].

This current study has used Rockart's guidelines for developing a CSF model [15]. According to Rockart, a CSF model addresses two key components, which are (a) identification of factors and (b) determination of their relative importance:

Factor identification: Factor identification requires determination of the level of analysis as well as the identification techniques. Among different levels of analysis, the current study uses a firm specific level.
This level utilizes an emphasis on the firm's internal matters to provide a link to possible factors [15]. Furthermore, this study has used expert interviews as well as review of the literature and analysis of an online discussion forum as the identification techniques.

Relative importance: next, a CSF model needs to demonstrate the relative importance of the factors identified in the previous step. Relative importance indicates which factors have a higher likelihood of helping a business to achieve particular goals [15]. This study has used Q-sort methodology in order to determine the relative importance of the factors. This method searches for connections between topics spanning a variety of factors. These varying viewpoints that come from the result of the survey are then reduced down into a few factors that are a representation of common ways of thinking about that topic. These data sets are collected from participants by their ranking of a number of "Q sorts". This enables a picture to be gathered about the topics in relation to each other, rather than individually.

\subsection{Activity Theory}

Activity Theory explains organizations' focus and their purpose of using a particular initiative. In this theory, the object (the thing being done) of an activity identifies the activity's purpose and intention, while a subject is an individual or a group which undertakes an activity with particular motive(s) $[16,17]$. When used in the context of social networking sites (SNSs), Activity Theory can provide a holistic and insightful way of describing how organizations may use the same tool (i.e. Facebook) for a particular purpose (i.e. customer relationship management). An activity may influence or maybe influenced by its social context [16], and thus different subjects may perform an activity differently and may achieve different outcomes from a similar activity. It is important, according to this theory, to critically analyze and identify significant activities of organizations as well as the actions that they take for achieving particular purposes.

The notions suggested by Activity Theory therefore have motivated this study to examine organizations' purpose of using SNSs for CRM. To this end, this study uses a set of three sources for determining the key ways and factors that SMEs use for using Facebook for CRM purposes: 1) SNS and other related literature, 2) digitalpoint.com, a website for online discussion about SNSs, 3) interviews with practitioners and experts. By collecting data from these sources, it is expected that by achieving a comprehensive set of activities undertaken by organizations, a roadmap for 
other organizations can be recommended for a successful social CRM on the Facebook platform

\section{Data Collection}

\subsection{Factors from the literature}

This section reviews the SNS literature to extract factors, which may play a role in customer relationship management on social networking sites. A review of the literature in the fields of 'social networking sites', 'customer relationship management' has been conducted on scholar.google.com to find papers that have explicitly reported one or more factors relevant to this study. Gu et al [18] examined customer loyalty for social network sites and found that perceived value, satisfaction, and consumer knowledge are important factors for maintain customer loyalty. Social CRM provides a platform for open communication between companies and their customers [19]. This platform has a number of important characteristics including: a conversation-centric platform, all customers can participate in the market, tools are available for community management, a dynamic and evolving environment, sustained customer engagement, and many to many relationships between customers and companies.

Kaplan and Haenlein [4] have investigated the use of social media by organizations, and suggest 10 pieces of advice for companies to consider when deciding to use social media: 1) choose the right social media based on the group target to be reached and the message to be communicated, 2) analyze and decide whether it is more beneficial to join one of the existing social media applications or to make your own platform, 3) make sure that all social media activities are aligned with each other, 4) integrate the social media activities, 5) give right access to the employees of the company to be able to contribute to company's social media activities, 6) be active in giving fresh content and in engaging with customers, 7) be interesting, 8) be humble, 9) be professional, and 10) be honest.

Nonprofit organizations have also been encouraged to use social networking sites in various ways, such as online causes, and to be transparent in communication with their users [20]. Organizations should provide a description of their business, tell stories about their activities, provide videos and pictures to establish connection with users, and make contact details of the individuals who are responsible for maintaining the social networking site available for users. It is important that social networking sites properly manage distribution of information in a form of posting links to external websites and news content, provide information about the organization and its activities, post added value information such as videos and pictures, and create discussion forums or spaces to answer users' questions and post announcements [21].

Online advertisement in social media and search engine environments is growing rapidly and becoming increasingly complex [22]. Advertisers should increasingly rely on third party experts and more advanced tools to improve the efficiency of their campaigns. For example, third party experts can help organizations to identify the most appropriate search terms and how much to bid on them [22]. Organizations therefore must closely monitor the outcomes of their online activities through using analytic tools.

Organizations need to have competencies in keyword selection, managing and monitoring performance, realizing click fraud and integrating paid search with other forms of advertising [23]. Another important factor in using search engine advertising is commitment to constant monitor, as many organizations rarely monitor their advertising performance [23].

A survey of 95 companies found that advertisers have serious difficulties in measuring achievements and outcomes of their marketing practice [24]. They also highlighted that advertisers must analyze and measure their marketing outcomes with appropriate tools and feed them back into their strategic decision making process. A lack of knowledge and expertise in the field as well as commitment to the campaign by dedicating adequate amounts of time, budget and resources, and managing keywords were among other difficulties organizations have experienced.

Another study found that poor marketing planning, lack of e-marketing expertise and competencies, lack of training, lack of commitment (not assigning enough resources), and absence of measuring and monitoring PPC effectiveness are the key factors are factors that act as deterrents in achieving PPC success and effectiveness [25].

Managing and tracking tools are playing an important role in communicating with users through search engine and social media advertisement [26]. In particular, independent third party tools are helpful in handling the advertising campaign when the campaign becomes more complex, and that sometimes it is essential to have an expert backing up how the campaign is progressing.

An assessment of content of 275 nonprofit organizations on Facebook found that while these organizations have created a Facebook profile with some information about their organization and links to external news websites, they failed to take advantage 
of various available communication opportunities on Facebook [27]. For example, these organizations had rarely used videos and pictures taken by their volunteers, press releases, and information their companies and activities.

All factors from the above studies were considered. Repeated factors were removed and similar ones were then consolidated. Based on the factors' meanings, a name was chosen for the consolidated factors. Below is the list of the resulted factors without any order:

1) Ability to measure \& monitor outcomes

2) Level of knowledge and expertise about SNS

3) Being committed to SNS task

4) Using external experts

5) Integrating SNS activities with other forms of marketing

6) Connecting SNS Ads to appropriate landing page

7) Ability to detect click frauds

8) Relevancy of Ad text to search terms

9) Provide an added value within your campaign (e.g. iPhone application, a product forum, videos)

10) Let the users/consumers participate

11) Regular updates on the SNS

12) Try to be honest and authentic during the campaign

13) Try to tell a story about your organization

14) Company's experience in SNS

15) Be, work, and think customer-centric

16) Understand that social networking channels are different from each other and need separate attention

17) Prepare/train your employees

\subsection{Factors from Forums.digitalpoint.com}

The second source of data for this study is Forums.digitalpoint.com. Online textual discussions are rich and insightful sources of information for user behaviour preferences and analysis [28,29]. This study has examined the content of a forum on Forums.digitalpoint.com to investigate the factors that forum members found important for organizations to communicate with users on Facebook. DigitalPoint is a large website which contains business and information technology discussion forums such as search engines, online marketing, social networks and website design and development. DigitalPoint helps new and professional web users to ask questions and exchange ideas and experiences and to participate in discussions on a variety of topics related to the digital world. It is free for users to register and participate in the forums. DigitalPoint has strict rules and policies, which maintain the quality and relevance of forum discussions.
A thematic analysis technique has been used to capture the presence and frequency of occurrence of concepts presented in the text either explicitly (as a word or a phrase) or implicitly [30]. Themes are patterns across data sets, and in this paper words or concepts related to interaction with customers on SNSs and Facebook have been considered as themes. A six steps method has been used for this analysis [31]: (1) familiarization with data: the online Facebook forum has been carefully examined to get familiarized with the different types of messages posted to this forum; (2) generating initial codes; any content in relation to organizations' interactions with customers on their Facebook page have been considered a relevant content for coding and unrelated content has been removed from the analysis. The content of all discussions was copied into Nvivo software as a raw file. Message threads were then carefully read and information in relation to customer relationship strategies or solutions to any issues was identified with different colors; (3) searching for themes among codes; the colored codes were assessed and the similar ones were aggregated as a specific theme. For each theme a node was created in the Nvivo software program and relevant content to that theme were copied into that node; (4) reviewing themes; these themes were then reviewed and those with a similar meaning were consolidated and their corresponding nodes and content were merged; (5) defining and naming themes; the final achieved themes were considered as strategies for communicating with customers on organizations' Facebook page. These strategies were then named based on the meaning they reflected; (6) producing the final report: a list of final strategies have then been emerged and developed.

At the time of analysis, February 2012, more than 2600 threads of discussions were available in this forum, covering a variety of topics with some threads having more than 100 responses from the members. Firstly, threads with no responses were removed. Also those threads with irrelevant topics to the objectives of this study, such as participants' favorite games and applications or making money on Facebook, were excluded from analysis. This left 300 threads for analysis. The content of the selected threads were then transferred to Nvivo for analysis. Thematic analysis was used as explained earlier to capture the presence and frequency of occurrence of factors that were related to communication with users on Facebook. A name was then assigned to each extracted factor. Finally, to examine inter-rater reliability of coding, a $\mathrm{PhD}$ graduate was recruited and trained to randomly select twenty percent of the total messages and code them based on instructions provided. Results showed an acceptable inter-rater reliability of 0.88 . 
These factors are shown in Table 1. This table also shows examples of quotes for each factor.

Table 1: Factors extracted from Digitalpoint.com

\begin{tabular}{|c|c|}
\hline factors & f quotes \\
\hline $\begin{array}{l}\text { Provide an added } \\
\text { value within your } \\
\text { campaign }\end{array}$ & $\begin{array}{l}\text { Update your page with cool content } \\
\text { [and products] }\end{array}$ \\
\hline $\begin{array}{l}\text { Contribute to other } \\
\text { similar fan pages }\end{array}$ & $\begin{array}{l}\text { Post your page link on those pages } \\
\text { who have thousands of like's you } \\
\text { will get results. }\end{array}$ \\
\hline $\begin{array}{l}\text { Regular updates on } \\
\text { the SNS }\end{array}$ & $\begin{array}{l}\text { You need to do regular activity on } \\
\text { page so that people don't loose } \\
\text { interest }\end{array}$ \\
\hline $\begin{array}{l}\text { Being committed to } \\
\text { SNS task }\end{array}$ & $\begin{array}{l}\text { No one will like it if they don't } \\
\text { know about it. And there's no sugar } \\
\text { coating it, it's a lot of work, and it'll } \\
\text { require you time and/or money. }\end{array}$ \\
\hline $\begin{array}{l}\text { Design appealing } \\
\text { page }\end{array}$ & $\begin{array}{l}\text { It pays if the copy and layout } \\
\text { published in Facebook is appealing } \\
\text { to the demographic. }\end{array}$ \\
\hline $\begin{array}{l}\text { Be thoughtful and } \\
\text { have a plan }\end{array}$ & $\begin{array}{l}\text { One thing you might want to } \\
\text { consider is to figure out who } \\
\text { exactly is your target audience, } \\
\text { what makes them excited, why they } \\
\text { come on your site. Give them } \\
\text { something to be excited about. }\end{array}$ \\
\hline $\begin{array}{l}\text { Be, wor } \\
\text { custome }\end{array}$ & $\begin{array}{l}\text { Listen what they [customers] are } \\
\text { saying; Increase engagement with } \\
\text { the fans. This way you can create a } \\
\text { community around your fan page } \\
\text { who would visit the page } \\
\text { frequently. }\end{array}$ \\
\hline Use $\mathrm{Fac}$ & oook \\
\hline $\begin{array}{l}\text { Integrating SNS } \\
\text { activities with other } \\
\text { forms of marketing }\end{array}$ & $\begin{array}{l}\text { Connecting to your other social } \\
\text { networking site accounts; Link to } \\
\text { Twitter }\end{array}$ \\
\hline $\begin{array}{l}\text { Provide give away } \\
\text { information about } \\
\text { products \& services }\end{array}$ & $\begin{array}{l}\text { Offer discounts and promos - } \\
\text { Limited time offers }\end{array}$ \\
\hline $\begin{array}{ll}\text { Using } & \text { external } \\
\text { experts }\end{array}$ & $\begin{array}{l}\text { I have a man who can Deliver a lot } \\
\text { of } 100 \% \text { original fan as you want } \\
\text { by some money. If you interested } \\
\text { send me a PM. }\end{array}$ \\
\hline
\end{tabular}

In comparison to the factors discovered in 3.1 , this section found a number of following new factors:

- Develop a strategic SNS plan: This plan has to outline SNS missions and long term development activities and also it needs to address strategies for dealing with negative comments and their potential consequences. In addition, forum participants stressed that a strategic plan need to identify target customers and develop the content based on their interest.

- Contribute to other similar community pages: this will help organizations to attract new users to their
Facebook page and also to learn about strategies other organizations use to interact with users.

- Use Facebook paid advertising: Forum participants found Facebook advertising a useful tool in attracting new users to the organization's page for promoting new products and services and also for promoting events and discounts.

- Provide a lot of giveaway information: Facebook users like free and relevant information. When organizations provide giveaway information, users are more likely to join the organization's page and regularly check it.

- Design appealing pages: In particular, forum participants indicated that a quality design for the 'welcome page' to give a good first impression to users is important. For example, organizations can use Facebook tools, such as iframe, to incorporate a mini version of their website into their Facebook page.

\subsection{Factors from Interviews}

Interviews are useful when CSF models are used as an information system-planning tool to provide recommendations to managers $[12,15]$. Twenty Australian organizations were interviewed in this study in two rounds. Appendix 1 shows the questions asked in the interviews.

Snowball sampling was used to recruit participants for the interviews. Table 2 shows their background information. The objective of the first round was to explore the factors that were important in using Facebook for communicating with users from users' point of view. The second round of interviews aimed to rank all factors based on their perceived importance.

Table 2: Interviewees' background information

\begin{tabular}{|l|l|l|l|l|l|}
\hline \multicolumn{3}{|c|}{ Organization size } & \multicolumn{3}{|c|}{ Organizational role } \\
\hline $20=<$ & $\begin{array}{l}>20 ; \\
<=100\end{array}$ & $>100$ & $\begin{array}{l}\text { SNS } \\
\text { manager }\end{array}$ & $\begin{array}{l}\text { Marketing } \\
\text { manager }\end{array}$ & $\begin{array}{l}\text { SNS } \\
\text { analyst }\end{array}$ \\
\hline 10 & 8 & 2 & 8 & 8 & 4 \\
\hline
\end{tabular}

Interviews started by outlining the objectives of the research and explaining the notion of critical success factors for organizations. The first round of the interviews included only open-ended questions, with questions exploring the reasons organizations embarked on a presence on Facebook, their experience with how they used Facebook for interacting with customers, and the factors participants found important in using Facebook to interact with users. On average, interviews took 1.5 hours, with frequent elaboration and clarification on each factor. 
Participating organizations were from different industries. Most of them had started their presence on Facebook after 2010, with two starting in 2009 and 2008.

The first round of the interviews was concluded by explaining the notion of critical success factors to the participants and asking them to nominate three to five critical factors that an organization would not survive without carefully considering them. After consolidating the nominated factors from all interviews, nine factors were identified. Out of these nine factors, the following five factors had already been identified in sections 3.1 and 3.2:

- Develop a strategic SNS plan

- Provide an added value within the campaign (e.g. iPhone application, a product forum, videos)

- Train employees

- Regular updates on SNS page

- Be committed to the SNS task

And the following four factors had not been previously identified in sections 3.1 and 3.2:

- Target your audience and provide relevant information: Organizations need to identify and target their audience. It is important for organizations to understand who their audience is and why they have joined the organization's Facebook page. Organizations then need to prepare and provide information according to their audience's needs. Organizations should therefore avoid uploading videos, pictures, and other information, which are unrelated to the audience.

- Avoid unethical issues: Unethical behaviors and information can quickly go viral on social networking sites and have to be avoided. It is important for organizations to have procedures and/or policies which oversea the content of their Facebook page.

- Load the Facebook page with appropriate keywords: Users more and more use Facebook to search for products and services and organizations need to ensure they load their page with a lot of relevant keywords.

- Invite high profile people to the Facebook campaign: One useful way to attract and retain users is to regularly invite high profile people to the organization's Facebook page. This significantly increases traffic and may enhance attractiveness of the organization's products or services.

\section{Ranking Factors}

Q-sort methodology was used to measure relative importance of the factors. The objective was to identify which factors are 'more important' than others, so that a small group of critical factors can be distinguished. Q-sort methodology has been designed to measure human subjectivity and viewpoint [32]. While normal factor analysis examines correlation between variables, Q-sort methodology looks for correlations between subjects across a sample of variables. Q-sort method works well with small sample sizes, as statistical reliability or generalizability of the findings to the whole population is of less concern and as the results of this method are the discrete subjective about a measureable concept.

A Q-sort is ranking of statements in accordance with a question or statement. In this method a large number of concepts are presented to respondents who are asked to sort them on a scale of 5 or 7 . Respondents need to compare each particular concept or factor against the question and place it under one of the five categories. This will categorize factors into five categories, where the most important category is ' +2 ' and the least important one is ' -2 '. Next, Q-Sort methodology will require the respondents to compare each factor with other factors under the same category and change the order of factors according to their importance.

In the second round of interviews, the interviewees were asked to rank the factors using Q-sort methodology. Interviewees who participated in the first round were all invited and participated in the second round. They were invited to elaborate on their point of view on each factor and rank them on a scale of 5 . The results of this ranking have been summarized in Table 3. As this table shows, relative importance levels ' +1 ', and ' +2 ' have been used as the cutoff point, and thus the factors within these importance levels have been considered as the critical success factors for customer relationship management on social networking sites.

Table 3: Ranking the Factors

\begin{tabular}{l|l|l}
\hline Group & \multicolumn{1}{|c|}{ Factors } & Rank \\
\hline \multirow{5}{*}{+2} & Let the users/consumers participate & 1 \\
\cline { 2 - 3 } & Regular updates on the SNS & 2 \\
\cline { 2 - 3 } & Be, work, and think customer-centric & 3 \\
\cline { 2 - 3 } & $\begin{array}{l}\text { Try to be honest and authentic during } \\
\text { the campaign }\end{array}$ & 4 \\
\cline { 2 - 3 } & $\begin{array}{l}\text { Integrating SNS activities with other } \\
\text { forms of marketing }\end{array}$ & 5 \\
\hline+1 & $\begin{array}{l}\text { Ability to measure and monitor } \\
\text { outcomes }\end{array}$ & 6 \\
\cline { 2 - 3 } & Develop a strategic SNS plan & 7 \\
\cline { 2 - 3 } & Being committed to SNS task & 8 \\
\hline \multirow{5}{*}{} & $\begin{array}{l}\text { Target audience and provide relevant } \\
\text { information; }\end{array}$ & 9 \\
\hline
\end{tabular}




\begin{tabular}{|c|c|c|}
\hline \multirow{11}{*}{0} & Prepare/train your employees & 10 \\
\hline & Avoid unethical crisis & 11 \\
\hline & $\begin{array}{l}\text { Connecting SNS Ads to appropriate } \\
\text { landing page }\end{array}$ & 12 \\
\hline & Relevancy of Ad text to search terms & 13 \\
\hline & Invite high profile people to your page & 14 \\
\hline & $\begin{array}{l}\text { Understand social networking channels } \\
\text { are different from each other \& need } \\
\text { separate attention }\end{array}$ & 15 \\
\hline & Use Facebook paid advertising & 16 \\
\hline & $\begin{array}{l}\text { Contribute to other similar fan pages } \\
\text { specially high profile pages and groups }\end{array}$ & 17 \\
\hline & $\begin{array}{l}\text { Provide an added value within your } \\
\text { campaign (e.g. iPhone application, a } \\
\text { product forum, videos) }\end{array}$ & 18 \\
\hline & $\begin{array}{l}\text { Load Facebook page with appropriate } \\
\text { keywords }\end{array}$ & 19 \\
\hline & Design appealing page & 20 \\
\hline \multirow[t]{3}{*}{-1} & $\begin{array}{l}\text { Level of knowledge and expertise } \\
\text { about SNS }\end{array}$ & 21 \\
\hline & Company's experience in SNS & 22 \\
\hline & Ability to detect click frauds & 23 \\
\hline \multirow[t]{2}{*}{-2} & $\begin{array}{l}\text { Try to tell a story about your } \\
\text { organization }\end{array}$ & 24 \\
\hline & Using external experts & 25 \\
\hline
\end{tabular}

\section{Analysis and Discussion}

Analysis of the factors suggests that different organizations use Facebook differently and achieve different results. While some organizations had a considerable awareness of Facebook capabilities, others were still trialing its features. This is in line with Activity Theory, as the theory suggests an activity may influence or maybe influenced by its social context [16], and thus different subjects may achieve different outcomes from a similar activity. A critical success factor model identifies a small number of factors that are essential for organizations to succeed. This study therefore considered factors with a relative importance of ' +1 ' and ' +2 ' as those few factors that organizations need to pay particular attention to successfully use SNSs for customer relationship management. Factors in this group demonstrate two distinguishable themes:

- A customer-centric approach to the SNS campaign: This theme includes four factors, (i) Let the users/consumers participate, (ii) Be, work, and think customer-centric, (iii) update your SNS page, and (iv) Try to be honest and authentic during the campaign. This theme highlights the importance of an honest and close relationship with users on social networking sites. The theme emphasizes that organizations need to provide a dynamic environment in which contents are regularly updated, users can freely participate in the campaign, and quick and appropriate responses to both positive and negative comments are provided.

- Developing an SNS strategic plan: Three factors fall into this theme: (i) Develop a strategic SNS plan, (ii) Ability to measure and monitor outcomes, and (iii) Being committed to SNS task. These factors emphasize that a successful campaign on SNSs requires organizations to develop a strategic plan which outlines organizations' objectives and goals, to integrate SNS activities with other forms of online and offline marketing, and to measure the performance of their SNS campaign.

The above CSFs stress that the key step for organizations to succeed in an SNS campaign is development of a strategic plan built around a dynamic and active customer relationship management, which clearly identifies objectives and regularly measures and monitors the expected outcomes.

The next group of the factors in Table 3 comprises factors with a medium importance level, or ' 0 ', in the Q-sort method range. Factors in this group play a 'supportive role' by helping organizations to more effectively implement the CSFs in 'group one'. They have been categorized into three themes:

- Training and development of human resources: The two factors in this theme (i) Prepare/train your employees and (ii) avoid unethical crisis, demonstrate the importance of using knowledgeable staff for SNSs campaigns. SNS staff needs to understand the difference between the SNS environment and other communication channels with customers. This is important not only for an effective communication with SNSs users, but to avoid any crisis due to the organization's unethical actions or inappropriate responses to the customers' behavior on the organization's Facebook page.

- Relevant content: Two factors shape this theme (i) Target audience and provide relevant information, and (ii) Provide an added value within your campaign (e.g. iPhone application, a product forum, videos). They show that it is necessary for organizations to understand who their Facebook page visitors are and what they want, and then feed their page accordingly. Organizations should also make their page more appealing by adding interactive content, such as videos and relevant applications.

- Attract and attain customers by advertisement and appealing design: The factors in this theme are (i) Connecting SNS Ads to appropriate landing page; 
(ii) Invite high profile people to your page; (iii) Use Facebook paid advertising; Design appealing page; (iv) Contribute to other similar fan pages specially high profile pages and groups; (v) Relevancy of Ad text to search terms; (vi) Load Facebook page with appropriate keywords. These factors demonstrate that as people are increasingly using social networking sites to search for products and services as well as communities and groups, organizations need to make sure their Facebook page is loaded with appropriate keywords and is linked to their website and other relevant online communities. Furthermore, while it is easy for any organization to create a page on Facebook, few organizations put sufficient efforts into making their pages look good and appealing.

Lastly, the rest of factors have been categorized as ' -1 ' and ' -2 ', meaning that they have the least importance in organizations' attempt to use SNSs for customer relationship management. These groups include four factors: (i) Level of knowledge and expertise about SNS; (ii) Company's experience in SNS; (iii) Ability to detect click frauds; and (iv) Try to tell a story about your organization. Lower scores for these factors may indicate that they do not need urgent attention from organizations for communication with users at early stages of SNS adoption. Perhaps considering these factors at the later stages of SNS adoption may help organizations to concentrate on more important factors and to more efficiently achieve the desirable outcomes.

\section{Conclusion and Future Studies}

The growing popularity of social networking sites has encouraged many businesses to embark on establishing a presence on these sites and, in particular, on Facebook. Despite the simplicity of creating a business page on Facebook and ease of use of its content generation tools, many businesses are unsure of factors they need to consider when they use Facebook to communicate with their potential and current customers. One reason that organizations have not yet been successful in their adoption of SNSs is that they have a lack of understanding of what these websites are, and what priorities organizations need to consider when they embark on establishing a presence in social media [4]. Also according to Activity Theory, often what organizations may seem to be doing might be different from what they actually planned to do, or even different from what they actually do. This may explain why amongst many organizations on Facebook, only some of them believe their Facebook activities pay off and that they should continue and capitalize on what they have been doing. Whereas many other organizations are unsure about how to properly use Facebook for CRM purposes and how to ensure about its return on investment [7, 17]. This study is an attempt to address this gap in the literature by analyzing the literature as well as the content of online discussions and SNS experts' opinions, and identifying a set of critical success factors (CSFs) that organizations need to use for successfully communicating with users.

These CSFs in particular emphasize that organizations need to develop a strategic plan for SNS campaigns, which clearly identifies objectives and regularly measures and monitors the expected outcomes, and which is built around a dynamic and active customer relationship management. The findings of this study show that many organizations are still unsure of their objectives from having a presence on Facebook. Mainly they are there just because their competitors are on Facebook.

Many small to medium size organizations do not have a written plan for resource allocation and development of their presence on Facebook. Furthermore, most of these organizations consider social networking sites and Facebook as an advertising tool, where they push promotional information. Yet, the findings of this study show Facebook should be looked at as a tool for developing a close relationship with customers, where information is provided to inform and educate customers. Facebook campaigns should be used to create a community and where customers feel they are part of the community. This may further encourage them to contribute to the Facebook campaign in different ways. For example, in one of the participating organization's Facebook page, customers helped other customers by responding to their inquiries much earlier than the organization did. Some customers were also actively contributing to product development and customer services by providing suggestions. These types of behaviors were mainly motivated by the organization's close relationship with customers, established mainly as a result of honesty with customers in regards to products and services characteristics and their terms and conditions of use as well as price and complaint handling structures.

In addition, this paper has identified a set of other factors that, while they are also important for a successful use of Facebook for communication with users, they may be considered at a lower priority and be looked at as guides and implementation tools which help organizations to achieve the critical success factors. 
The factors identified in this research can be input for future studies for empirically assessing the extent to which organizations successfully communicate with SNSs users and for identifying the areas organizations may need to improve for enhancing their presence on SNSs. The findings of this study may also be used as guidelines for organizations for development of an SNS strategic plan and for measurement of their performance on social networking sites. Furthermore, while many participating organizations found Facebook a good way for communicating with customers, the return on their investment for an active presence on this website is still unclear for them. That ambiguity discouraged many organizations from extending their services on Facebook. Future studies could therefore define a return on investment on SNSs campaigns and investigate whether or not, and also to what extent, an investment on Facebook, in particular, and on SNSs, in general, would be worthwhile for organizations.

\section{Appendix 1: Interview Questions}

1. When did your organization embark on a presence on Facebook? What motivated your organization to do so?

2. Approximately what percentage of your organization's total annual advertising budget is allocated for advertising on the Facebook? Do you plan to increase this budget in a near future?

3. Please describe the most important benefits of using Facebook for communicating with customers for your company

4. Please describe the most important challenges and issues your company has experienced by using Facebook for communicating with customers

5. How did you organization use Facebook to communicate with your customers? Please explain the extent to which your organization has integrated Facebook with other current CRM practices.

6. Does your organization use any formal or informal ways for measuring the performance of your Facebook campaign for CRM purposes?

\section{References}

[1] Mousavi, Seyedreza, and Haluk Demirkan. "The Key to Social Media Implementation: Bridging Customer Relationship Management to Social Media." System Sciences (HICSS), 2013 46th Hawaii International Conference on. IEEE, 2013.

[2] Greenberg, P. (2010). The impact of CRM 2.0 on insight. Journal of Business \& Industrial Marketing, 25(6), 410-419. M. N. K. Boulos, S. Wheeler. The emerging Web 2.0 social software: an enabling suite of sociable technologies in health and health care education. Health Information \& Libraries Journal, 24 (2007) 2-23.

[3] Lehmkuhl T., Jung R., (2013). Towards Social CRMScoping the Concept and Guiding Research. BLED 2013 proceedings, 190-205

[4] A. M. Kaplan, M. Haenlein, Users of the world, unite! The challenges and opportunities of Social Media. Business Horizons, 53 (2010) 59-68

[5] Poyry, Essi, Petri Parvinen, and Tuuli Malmivaara. "The Power of'Like'--Interpreting Usage Behaviors in CompanyHosted Facebook Pages." System Sciences (HICSS), 2013 46th Hawaii International Conference on. IEEE, 2013.

[6] Baird, C. H. and Parasnis, G. From social media to social rela-tionship management. Strategy \& Leadership. 39 (5), 2011. 30-37

[7] Trainor K.J., Andzulis J., Rapp A., Agnihotri R., (2013). Social media technology usage and relationship performance: A capabilities-based examination of social CRM. Journal of Business Research. In Press

[8] D. M. Boyd \& N. B. Ellison, Social Network Sites: Definition, History, and Scholarship. IEEE Engineering Management Review, 38 (2011) 16-31.

[9] G. Pallis, D. Zeinalipour-Yazti, M. D. Dikaiakos, Online social networks: Status and trends. Studies in Computational Intelligence, 331(2011) 213-234

[10] Wu J., Sun H., Tan Y., (2013). Social Media Research: A Review. Journal of Systems Science and Systems Engineering. 22(3) 257-282

[11] Clemons E. K., Barnett S., \& Appadurai A., The Future of Advertising and the Value of Social Network Websites: Some Preliminary Examinations. Proceedings of the ninth international conference on Electronic commerce. New York, NY, USA, ACM, 2007

[12] Boynton A. C., Zmud R.W.. An Assessment of Critical Success Factors. Sloan Management Review, 25(4) (1984) 17-27

[13] Kim S.H., Yang K.H., Kim J.K., Finding critical success factors for virtual community marketing. Service Business, 3 (2009) 149-171.

[14] Li, Kai, et al. "Running and Chasing--The Competition between Paid Search Marketing and Search Engine Optimization." System Sciences (HICSS), 2014 47th Hawaii International Conference on. IEEE, 2014.

[15] Rockart JF, Chief executives define their own data needs. Harvard Business Review, 57(2) (1979) 81-93

[16] Hasan, H., and Meloche J. "Innovative ICTmediated activities for people, profit and planet." European Journal of Innovation Management 16.3 (2013): 335-354.

[17] Abedin B, Jafarzadeh H., (2013), Attracting and retaining customers on Facebook business pages: a content analysis of an online discussion forum, 8(3) 304-315

[18] Gu R., Oh L.B., Wang K., Determinants of Loyalty for Social Networking Sites. Exploring the Grand Challenges for Next Generation E-Business, Lecture Notes in Business Information Processing Volume 52, 2011, pp 206-212

[19] Olszak, C, \& Bartuś T. "Multi-Agent Framework for Social Customer Relationship Management Systems." Issues in Informing Science \& Information Technology 10 (2013).

[20] S.J. Berman, Abraham, B. Battino, L. Shipnuck, A. Neus. New business models for the new media world. Strategy \& Leadership, 35 (4) (2007) 23-30 
[21] Carrera P, Chiu C.Y., Pratipwattanawong P., Chienwattanasuk S., Ahmad S.F.S, Murphy J., MySpace, my friends, my customers. P. O'connor, W. Höpken, U. Gretzel (Eds.), Information and communication technologies in tourism 2008, Springer Verlag Wien, Vienna (2008) 94-105

[22] Rashtchy, S., Kessler, A. M., Bieber, P. J., Schenider, N. H., Tzeng, J. C. The user revolution: the new advertising ecosystem and the rise of the internet as a mass medium. Piper Jaffray. 2007

[23] Laffey D., Paid search: The innovation that changed the Web. Business Horizons, 50 (2007) 211-218

[24] C. Barry, D. Charlton, In search of search engine marketing strategy amongst SME's in Ireland. Communications in Computer and Information Science, 48 (2009) 113-124.

[25] Murphy H.C., Do small and medium-sized hotels exploit search engine marketing? International Journal of Contemporary Hospitality Management, 20 (2008) 90-97

[26] Mordkovich E., Mordkobich B., Pay-Per-Click Search Engine Marketing Handbook: Low Cost Strategies To Attracting New Customers Using Google, Yahoo \& Other Sear LULU. 2007

[27] Waters R.D., Burnett E., Lamm A., Lucas J. Engaging stakeholders through social networking: How nonprofit organizations are using Facebook. Public Relations Review. 35(2) (2009) 102-106

[28] Marra R., A Review of Research Methods for Assessing Content of Computer-Mediated Discussion Forums. Journal of Interactive Learning Research, 17 (2006) 243-267

[29] Abedin B., F. Daneshgar, J. D'Ambra, Pattern of non-task interactions in asynchronous computer-supported collaborative learning courses. Interactive Learning Environments, (2014) 1-17.

[30] Allard, S., Mack, T. R., Feltner-Reichert, M. The librarian's role in institutional repositories A content analysis of the literature. Reference Services Review, 33 (2005) 325 336

[31] Braun V., Clarke V.. Using thematic analysis in psychology. Qualitative Research in Psychology 3(2) (2006) 93

[32] Bouwman, Harry, Angel Bejar, and Shahrokh Nikou. "Mobile services put in context: A Q-sort analysis." Telematics and Informatics 29.1 (2012): 66-81. 